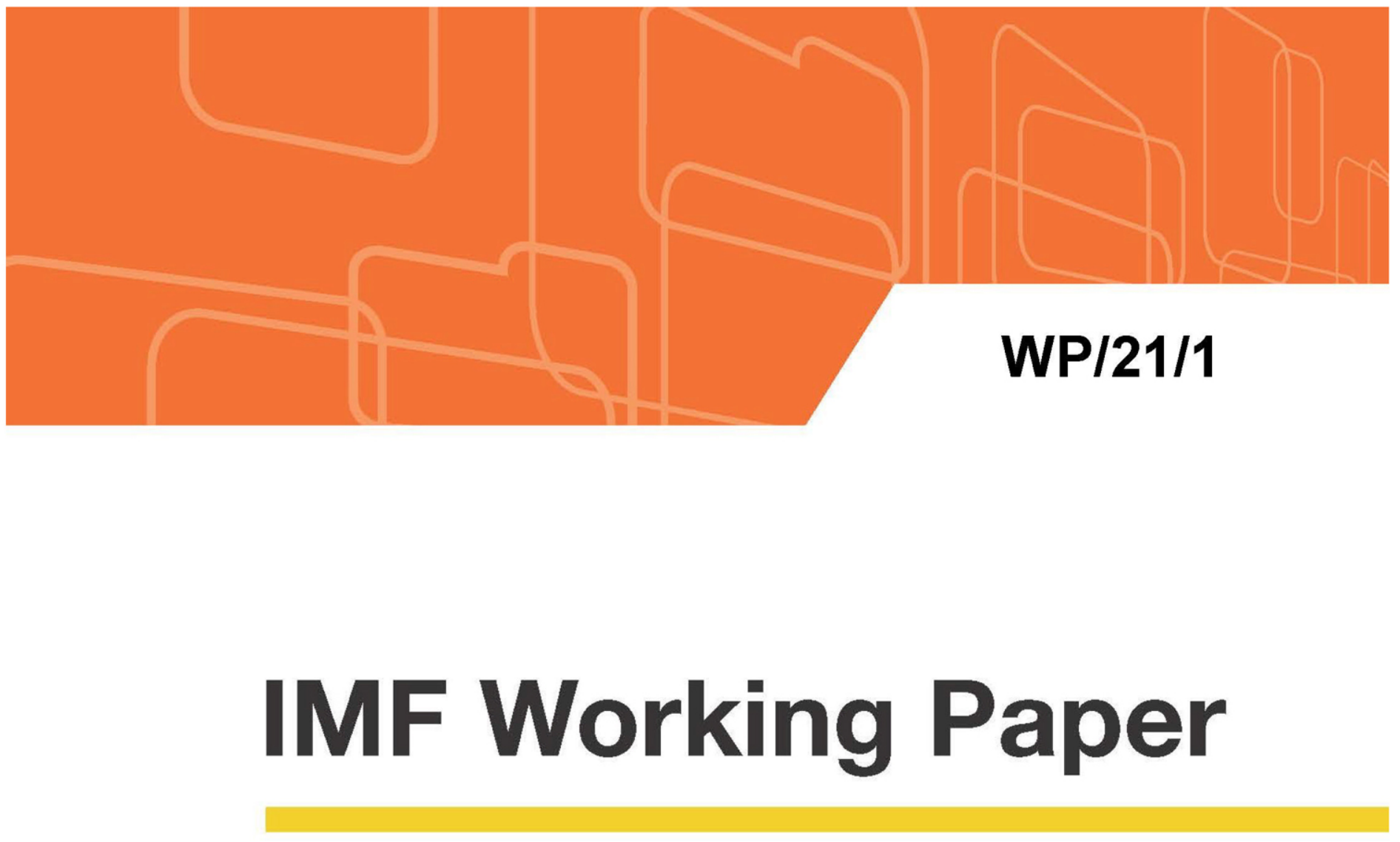

\title{
Politically Robust Financial Regulation
}

by Itai Agur

IMF Working Papers describe research in progress by the author(s) and are published to elicit comments and to encourage debate. The views expressed in IMF Working Papers are those of the author(s) and do not necessarily represent the views of the IMF, its Executive Board, or IMF management. 


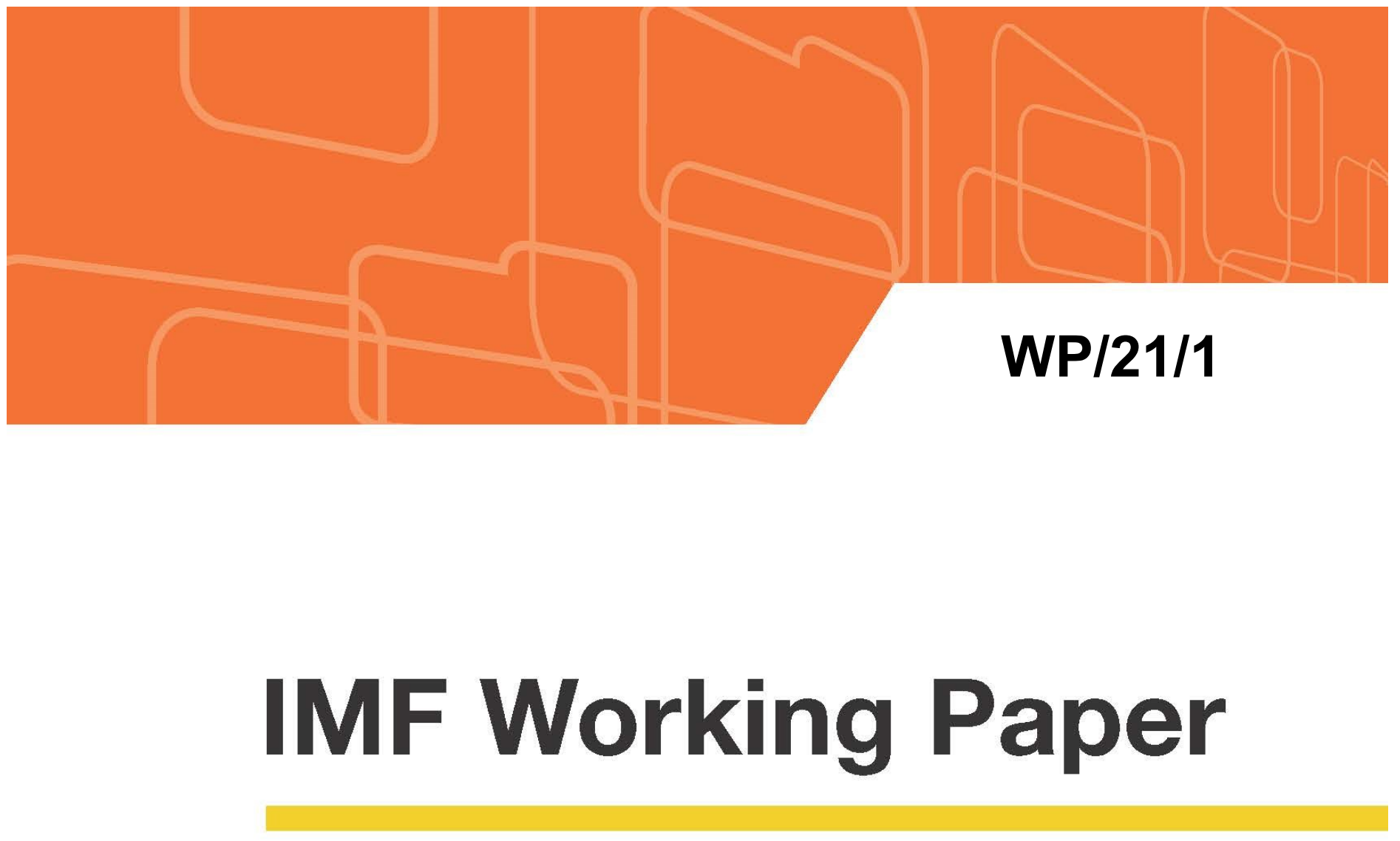

\section{Politically Robust Financial Regulation}

by Itai Agur

IMF Working Papers describe research in progress by the author(s) and are published to elicit comments and to encourage debate. The views expressed in IMF Working Papers are those of the author(s) and do not necessarily represent the views of the IMF, its Executive Board, or IMF management. 


\title{
IMF Working Paper
}

Research Department

\section{Politically Robust Financial Regulation'}

\section{Prepared by Itai Agur}

Authorized for distribution by Maria Soledad Martinez Peria

January 2021

\section{IMF Working Papers describe research in progress by the author(s) and are published to elicit comments and to encourage debate. The views expressed in IMF Working Papers are those of the author(s) and do not necessarily represent the views of the IMF, its Executive Board, or IMF management.}

\begin{abstract}
The deferred recognition of COVID-induced losses at banks in many countries has reignited the debate on regulatory forbearance. This paper presents a model where the public's own political pressure drives regulatory policy astray, because the public is poorly informed. Using probabilistic game stages, the model parameterizes how time consistent policy is. The interaction between political motivations and time consisten cy is novel and complex: increased policy credibility can entice the politically-motivated regulator to act in the public's best interest, or instead repel it from doing so. Considering several regulatory instruments, the paper probes the nexus of political pressure, perverse bank incentives and time inconsistent policy.
\end{abstract}

JEL Classification Numbers: C72, D82, G28, P16.

Keywords: Time inconsistency, Political economy, Financial stability, Bank regulation.

Author's E-Mail Address: iagur@imf.org.

\footnotetext{
${ }^{1}$ I am grateful to Anton Korinek, Maria Soledad Martinez Peria, Divya Kirti, Karsten Müller, Martin Čihák and Rachid Awad for insightful comments and discussions and would also like to thank audiences at the 3rd IMF Annual MacroFinancial Research Conference and the IMF RESMF Seminar for helpful comments.
} 


\section{Introduction}

In the dozen years since the onset of the Global Financial Crisis, the implementability of financial regulation has gained increased attention, including in empirical work on the link between regulation and politics. ${ }^{1}$ Political motivations can divert policy from a focus on the well-being of society, and are of particular importance for financial regulators, who often lack operational and financial independence (Agur and Sharma, 2014; Edge and Liang, 2019). Political pressure can, for example, lead a regulator to forbear when banks become insolvent. In turn, the foresight of its own future limitations affects the regulator's present-day incentives. The regulator thus faces not only the financial sector but also its own future selves, and must navigate its own changing mirror images, which can erode the credibility and the potency of current policy.

Two separate strands of the theoretical literature have explored the impact of, respectively, politics and policy credibility on the design of financial regulation. One strand examines how political economy factors bend the incentives of financial regulation. ${ }^{2}$ The other strand instead considers how time consistency affects such incentives. ${ }^{3}$ Both strands are of renewed relevance in light of the COVID-19 crisis, which has raised the pressure on regulatory policy to give precedence to the immediate needs of the financial sector and which may lower the priority given to longer term effects on policy credibility.

This paper brings both strands together, making a first foray into the intersection between the political economy and time consistency problems of financial regulation. It does so in a multi-stage game with three players: a policy maker, a bank, and the public. The public suffers from limited insight into the financial sector's health, and this forms the crucial information asymmetry in the model. The public can punish the policy maker, which it does when it learns of bank insolvency, because public taxes fund the deposit insurance. But because public insight into bank solvency is impaired, this ability to punish the policy maker is the very factor that pushes the policy maker away from maximizing the public's welfare. The policy maker here is the government as, consistent with the literature cited in footnote 2, we do not investigate inter-agency problems within the public sector. ${ }^{4}$ The government has an incentive to hide the revelation of bank insolvency, if there is a chance that the bank can return to health down the road. That is, the political economy

\footnotetext{
${ }^{1}$ Several seminal contributions predate the Global Financial Crisis (Brown and Dinç, 2005; Kroszner and Strahan, 1999; Nunez and Rosenthal, 2004; Rajan and Zingales, 2003; Romer and Weingast, 1991; Stratmann, 2002). However, recent years have seen a flurry of empirical research in this field (Agca et al., 2019; Behn et al., 2015; Benmelech and Moskowitz, 2010; Dagher, 2018; Dell'Ariccia et al., 2018; Edge and Liang, 2019; Igan and Lambert, 2019; Igan et al., 2017; Igan and Mishra, 2012, 2014; Igan et al., 2012; Liu and Ngo, 2014; Lucca et al., 2014; Mian et al., 2010, 2013; Müller, 2019; Shive and Forster, 2016; Veltrop and de Haan, 2014).

${ }^{2}$ See, e.g, Almasi et al. (2018); Bond and Glode (2014); Boot and Thakor (1993); Chang (2007); Gersbach and Papageorgiou (2019); Hakenes and Schnabel (2014); Herrera et al. (2020); Masciandaro and Passarelli (2013); RolaJanicka (2019); Tressel and Verdier (2014).

${ }^{3}$ See, e.g., Bianchi and Mendoza (2018); Colliard and Gromb (2018); Diamond and Rajan (2012); Ennis and Keister (2010); Farhi and Tirole (2012); Farhi and Werning (2016); Jeanne and Korinek (2019, 2020); Keister (2016); Keister and Mitkov (2019); Martynova et al. (2019); Morrison and White (2013); Shapiro and Skeie (2015); Walther and White (2020).

${ }^{4}$ Inter-agency and intra-agency problems in the conduct of regulatory policy are considered, for example, in the literature on whether central banks should have a mandate that encompasses bank regulation and supervision (Goodhart and Schoenmaker, 1995; Ioannidou, 2005).
} 
problem here is not an assumed bias, but rather an endogenous response to an information asymmetry. ${ }^{5}$

The bank can choose between projects with different risk profiles, and acts like a call option owner who sees primarily the upside of volatility. Thus, the model focuses on the negative side of risk-taking behavior, which emanates from the bank's exploitation of its public safety net. Moreover, if the bank chooses a risky project that initially performs poorly, its insolvency may not be the last step. The bank can gamble for resurrection by reinvesting funds in its underperforming but high-volatility project, hoping that a good draw can lead it back to profit. ${ }^{6}$

The gamble for resurrection is an activity that destroys net present value, and that should be prevented from a welfare perspective. Using a policy measure discussed below, the government can legislate against gambles ex-ante, before the bank has taken on any risk, and thereby hope to influence the bank's initial risk profile, which otherwise becomes tilted towards riskier projects by the prospect of a future gamble for resurrection. The government may also be able to act a second time, after the bank's initial solvency has already materialized. This second stage occurs with a certain probability. This represents the uncertainty about the government's nimbleness in response to financial sector developments, including crises, which in reality are fast paced compared to financial regulation.

However, being nimble is a double-edged sword when time consistency matters. If the government is certain to get a second decision stage, the government's initial legislation is cheap talk that can always be reversed. Instead, if the probability of the second stage is zero, the government's initial legislation is fully credible. By varying this probability, we obtain comparative statics to the degree of the time consistency problem in the model.

At its initial decision stage, the government essentially plays against two players: the bank and its own future self. In the play against the bank, the government's hand is strengthened by a more time consistent tool, because increased credibility gives it greater influence over the bank's risk choice. But, in playing against its future self, the government becomes tougher on initial regulation when its tool is less time consistent, as it wishes to lock itself in. We show that a marginal increase in time inconsistency can push the politically motivated government in either direction, making it either more or less inclined to protect public welfare through regulatory action. Therefore, sometimes policy credibility can backfire and lower welfare due to the interaction between time inconsistency and political motivations.

In the baseline model, the government's policy tool takes the form of mark-to-market accounting. Mandating such accounting causes the bank to directly mark itself down to negative equity when the risky project fails. Allowing the bank to continue using historical value accounting constitutes regulatory forbearance here, because it buys the bank time to engage in the gamble for resurrection. Following on the Global Financial Crisis, there has been an active debate on the relative

\footnotetext{
${ }^{5}$ Resolving this information asymmetry by transmitting the government's knowledge to the public is not compatible with the government's incentives: ex-ante it would like to commit to such revelation, but ex-post (if and when the bank is insolvent) it does not wish to reveal.

${ }^{6}$ This is modeled after the evergreening practices (also known as zombie lending) seen in the wakes of various financial crises. See, e.g, Acharya et al. (2019); Bergant and Kockerols (2020); Bonfim et al. (2020); Caballero et al. (2008); Peek and Rosengren (2005).
} 
merits of mark-to-market and historical cost accounting in the financial sector (Ellul et al., 2014). This comes down to a tradeoff between the risks from worsening regulatory forbearance, which our framework focuses on, and the risks from exacerbating shortages in liquidity and fire sales, as covered in, e.g., Adrian and Shin (2010), Allen and Carletti (2008), and Shleifer and Vishny (2010).

Two extensions consider alternative policy environments. In the first, the government acts only once, but designs state-contingent regulation, specifying under what conditions the bank may forgo mark-to-market accounting. In the second, the government can impose regulatory bounds on the bank's initial risk profile, but these bind with a probability, as the bank sometimes succeeds at arbitraging the restrictions. These alternative policy settings do not fundamentally alter the model's outcomes, unless success at binding bank risk is a certainty: outcomes are overturned by an ideal regulatory tool that gives the government complete control over the bank's risk taking incentives. However, the notion of an imperfect tool relates closely to the reality of financial regulation, where various tools affect risk taking incentives, but none achieve perfect control over them.

Put differently, at the bottom of the time inconsistency problem lies an incomplete set of policy instruments. The first-best, in which the bank never plays on the public insurance provided on its deposits, is attainable, but only when regulatory tools enable a perfect mapping from the desires of the policy maker to the actions of the bank.

Our model points at several elements that can help make financial regulation politically robust. First, the model formalizes the argument, previously made in policy discussions, that an informed public is essential for the effective implementation of financial regulation (Myerson, 2014). A second policy implication concerns the need for increased operational and financial independence for financial regulation (Fraccaroli et al., 2020; Sharma and Fullenkamp, 2012). In the context of our model, the notion of independence relates to the pressure that the policy maker feels from the public. When that pressure is small enough, which could occur if regulatory policy is placed in the hands of a sufficiently independent regulator instead of the government, the policy maker becomes untied from the informational problem of the public, and pursues policies that are ultimately in the public's best interest.

In the wake of the COVID-19 crisis, many policy makers have opted to defer loan loss recognition to shield banks and their creditors from the impact of the pandemic (International Monetary Fund, 2020). Indeed, the Basel Committee on Banking Supervision (2020) has provided specific guidelines for the implementation of measures like loan moratoria during the COVID-19 crisis. This paper does not necessarily provide ammunition to argue against such steps, which could be based on valid concerns about countering market dysfunctionality from liquidity shortages or fire sales. Instead, the paper points to the conditions that are needed for a policy maker to make an appropriate decision in this regard, particularly independence from pressures that can bias its decision. This is well-recognized as concerns the potential influence of industry lobbies (Igan and Lambert, 2019), but this paper shows that this also applies in relation to the public itself: its deficient information can be a source of bias.

This paper relates to both the strands of the literature referenced in footnotes 2 and 3, which are 
too extensive to review here. However, a few papers are most closely related. In Chang (2007), the government has a biased policy agenda and the public can punish it for this, but at a cost, which it is more willing to incur when a financial crisis looms. Like in our model, the government has an informational advantage relative to the public. However, the analysis of Chang (2007) centers on multiple equilibria, and the possibility that changes in the expectations of foreign lenders become self-fulfilling, rather than time consistency. Instead, in Morrison and White (2013) and Shapiro and Skeie (2015) timing takes center stage, as the regulator faces a repeated bailout problem and has an informational advantage: the need to build reputation arises endogenously. While such reputation-building can be seen as a political-economy feature, it is a socially optimal one. The political motivation that we model is neither a bias nor socially optimal. The sensitivity of the policy maker is towards the public, which it is supposed to serve, but this sensitivity can be socially detrimental when the public is poorly informed.

The remainder of this paper is organized as follows. Section 2 and 3 present the setup of the baseline model and its outcomes. Sections 4 and 5 consider the extensions of the model. Section 6 concludes. All proofs are contained in the appendix. ${ }^{7}$ A robustness exercise in a separate online appendix rederives the outcomes of the baseline model and the extensions using an alternative functional form for the bank's choice over risk profiles.

\section{Model setup}

There are three agents in the model: the bank, the government and the public, all of whom are risk neutral. We first describe their respective objectives and constraints in Sections 2.1-2.3, after which Section 2.4 lays out the timing of the game, which formalizes the interaction among the agents.

\subsection{The bank}

The financial sector is represented by a single bank that is managed by its owners. The bank's decisions center on its asset side, while its funding side is fixed and consists entirely of costless government-insured deposits. Bank owners are thus residual claimants that obtain the full upside of positive bank returns, and none of the downside in the event of bank insolvency. Furthermore, bank owners are considered a separate agent class that is not part of the public. ${ }^{8}$

On its asset side, the bank takes two decisions. First, the bank chooses its initial asset risk profile. Second, in the event that the bank becomes insolvent, it can choose to engage in a gamble for resurrection. We describe these choices, in turn.

\footnotetext{
${ }^{7}$ The algebraic derivations in the proofs are conducted in a Mathematica file that is available on request.

${ }^{8}$ Bank profits do not form a part of public welfare (Section 2.2). Implicitly, this can be seen as a Rawlsian representation of social welfare, centering on the well-being of the agents that are least well-off, which here are the members of the public that are not bank owners.
} 


\subsubsection{The bank's risk profile}

The bank starts off with a retail deposit base of size 1 . These deposits pay no interest and are never called (i.e., there are no bank runs). The bank chooses how to invest them, and can choose from a spectrum of projects. We use a linear functional form for this spectrum, which leads to tractable expressions and derivations. For robustness, this online appendix rederives the paper's results for a different (nonlinear) functional form.

The net return on bank assets, $r$, is drawn from a uniform distribution with mean $\mu$ and width $w$, where $w$ is defined such that the distribution ranges from $\mu-w$ to $\mu+w \cdot{ }^{9}$ For example, $\mu=0.02$ and $w=0.05$ would mean that the bank's net return on assets ranges from $-3 \%$ to $+7 \%$. Here, both $\mu$ and $w$ depend on the risk profile (or project), $\rho$, that the bank chooses. That is, the bank chooses from a continuum of possible distributions when determining $\rho$. In particular,

$$
\begin{aligned}
\mu(\rho) & =m-\alpha \rho \\
w(\rho) & =\beta \rho \\
\rho & \in[0,1]
\end{aligned}
$$

Due to its limited liability, the return structure of a risk-neutral bank bears similarity to that of a call option owner, who accrues the upside when the option is in-the-money, but has a bounded downside. Instead of the usual mean-variance tradeoff associated with risk aversion, the riskneutral bank trades off a higher variance ( $w$ increases as $\rho$ increases) against a higher mean return ( $\mu$ decreases as $\rho$ increases). This squarely centers the model on a choice between socially beneficial safer profiles and socially detrimental riskier profiles, which destroy actual project value, but gain option value for the bank by playing on its public safety net.

We let

$$
\begin{aligned}
\beta & >\alpha>0 \\
\alpha+\beta & <\frac{1}{2} \\
\alpha+\beta & >m>0
\end{aligned}
$$

where $\beta>\alpha$ means that, as $\rho$ rises, the width of the distribution (2) increases faster than the mean of the distribution declines (1), which opens up the possibility that the bank might prefer a riskier profile. Furthermore, $\alpha+\beta<\frac{1}{2}$ suffices to ensure that the bank's overall gross return, including gambles defined in 2.1.2, is nonnegative (i.e., the bank cannot lose more than its initial deposit base). Lastly, $\alpha+\beta>m>0$ means that the fixed part of the mean return in (1) is positive, but not so large that the bank's tradeoff always tilts towards the safest profile, because its

\footnotetext{
${ }^{9}$ Thus, the gross return on bank assets is $(1+r)$, and the expected gross return on the bank's investment of size 1 is $(1+\mu)$.
} 
limited liability option is too unlikely to be used. ${ }^{10}$

Taking account of its limited liability for $r<0$, the bank's expected profit is

$$
E[\Pi]=E[\max \{r, 0\}]=\int_{0}^{\mu+w} r f(r) d r
$$

where, from the uniform distribution,

$$
f(r)=\frac{1}{2 \beta \rho}
$$

Lemma 1 solves $E[\Pi]$ in closed form, and uses this to show that the bank either chooses the safest project, $\rho=0$, or the riskiest project, $\rho=1$. Which one it chooses depends on the mean return parameter $m$. This emanates from the well-known charter-value effect in bank risk taking (Keeley, 1990). ${ }^{11}$ The more skin-in-the-game a limited-liability bank has, the less inclined it is to take risk, because it has more to lose. In the terminology of option values, a high $m$ means that the option is deeper in-the-money, so that owning the option becomes more similar to owning the underlying asset, and there is little to gain from an increase in variance. Instead, a low $m$ means that high variance is valuable to the owner of the option.

Lemma 1 When considering (7) as the objective function of a one-shot optimization problem, the bank's optimal risk choice is given by ${ }^{12}$

$$
\rho=\left\{\begin{array}{l}
1 \text { if } m<\underline{m} \\
0 \text { otherwise }
\end{array}\right.
$$

where

$$
\underline{m}=\alpha+\beta-2 \sqrt{\alpha \beta}
$$

Proof. On page 24.

Given the binary optimal choice implied by Lemma 1 as well as the fact that $\rho=1$ is detrimental from a social perspective (lower mean return, and greater play on the safety net provided by taxpayers), we now refer to the bank's optimization as a choice between the good project, $\rho=0$, and the bad project, $\rho=1$. The bank chooses the bad project when the bank has relatively little at

\footnotetext{
${ }^{10}$ See the proof of Lemma 1 . Also note that, without loss of generality, we could further tighten (6) to $m>\alpha$ instead of $m>0$. With $m>\alpha$, all projects, including the $\rho=1$ project, always offer a positive mean return, per (1). In this case, all projects are value creating in expectation, but higher $\rho$ projects create less value and play more on the bank's limited liability. Note that with $m>\alpha$, conditions (4) and (6) would collapse to a single condition: $\beta>m>\alpha>0$.

${ }^{11}$ See also Agur (2014) for further discussion of the charter value effect.

${ }^{12}$ In this Lemma, and consistently throughout the paper, we ignore knife-edge cases where an agent is indifferent between outcomes, because these make no qualitative difference to our results. That is, (9) could equivalently be written with $m \leq \underline{m}$ without affecting the rest of the paper's analysis.
} 
stake, $m<\underline{m}$, so that the bad project offers the bank enough compensation in the form of higher option value to overcome the decline of $\mu$.

Overall, this setup, as summarized by the threshold condition in (10), allows us not only to consider a choice between a good and a bad project, but also to vary how perverse the bad project is in relation to the good project. Comparative statics to $m$, as well as $\alpha$ and $\beta$, which parameterize the bank's tradeoff, enable a rich analysis within a simple binary optimal choice setting.

Note that $\underline{m}$ represents the bank's decision threshold when its only objective is to maximize (7): other considerations, such as the possibility of gambling for resurrection and the constraints imposed by financial regulation, will shift this threshold.

\subsubsection{Gambling for resurrection}

Once the bank has chosen its project, and the return on that project has materialized, the bank may face an additional choice. In particular, if the bank has become insolvent, it could choose to engage in a gamble for resurrection. We model the bank's gamble for resurrection as a negative expected return activity. Gambling for resurrection is therefore socially harmful, and would always be prevented by a government with the policy tools to do so, provided that government is solely concerned with social welfare. This provides a stark setting in which to investigate the impact of political incentives.

We envisage the bank's gamble as zombie lending: a reinvestment in its failed project. With a probability of $g$ the gamble succeeds and boosts the net return on the bank's project by $(\alpha+\beta)$, which given (1)-(3) always suffices to bring the bank back to positive profit. But with probability $(1-g)$ the gamble fails, and the net return on the bank's project declines by an additional $(\alpha+\beta)$. Here, $g \in\left(0, \frac{1}{2}\right)$, which means that the expected return on the gamble is negative. Taking account of the possibility to gamble when insolvent (but not yet of possible government regulation) the bank maximizes:

$$
E[\Pi]=E[r \mid r>0]+E[g(r+\alpha+\beta) \mid r<0]
$$

Since an insolvent bank only sees an upside to the gamble for resurrection, it will always choose to engage in the gamble. Moreover, the option to gamble when the bad project fails, makes the bank more inclined to choose the bad project in the first place. The threshold value of $m$ below which the bank chooses the bad project becomes higher due to the option to gamble (i.e., there are more values of $m$ for which the bank chooses the bad project), as recorded in Lemma 2.

Lemma 2 The bank's solution to (11) in isolation (i.e., absent regulation) is

$$
\rho=\left\{\begin{array}{l}
1 \text { if } m<\bar{m} \\
0 \text { otherwise }
\end{array}\right.
$$


where

$$
\bar{m}=\frac{\alpha+\beta-2 \sqrt{\alpha \beta(1-g)+\frac{1}{4}(\alpha+\beta)^{2} g^{2}}}{1-g}
$$

and $\bar{m}>\underline{m}$.

Proof. On page 24.

\subsection{The public}

The public stands at the receiving end of the bank's risk taking. It bears the cost of bank insolvency, because the government's payout of deposit insurance is funded with (lump-sum) taxes levied on the public. From (7) the expected cost to the public from bank insolvency is $E[\min \{r, 0\}]$ when the bank does not have the option to gamble for resurrection. If the bank does have that option, then from (11) the expected loss to the public becomes $(1-g)(r-\alpha-\beta)$ when $r$ is smaller than zero, and the bank therefore gambles (i.e., the expected loss is $E[(1-g)(r-\alpha-\beta) \mid r<0]$ ). Instead, when $r$ is greater than zero, the public faces no bank insolvency costs. ${ }^{13,14}$

Although the public is aware that bank insolvency is costly to it, it is imperfectly informed about the health of the financial sector. The public does not have insight into the process that determines bank risk. The only bank variable that is visible to the public, but imperfectly so, is realized bank solvency, $r$. As long as the bank remains active, the public receives an imperfect signal about its health. Instead, if the bank is closed and deposit insurance is paid out, its true solvency position is revealed to the public.

The public's imperfect information about the bank's solvency is represented by a signal, $\theta \in$ $(0,1)$. This signal is a revelation probability: the public has a $\theta$ chance of knowing the bank's true solvency, $r$. This is so, unless the bank is closed, in which case the public always learns the bank's solvency, because a transfer of taxpayer money is involved. Therefore, the limit cases of $\theta \rightarrow 1$ and $\theta \rightarrow 0$, respectively, represent the cases of a perfectly informed public and a public that is completely in the dark as long as the bank is open for business. We assume that the public's prior is that the bank is solvent $(r \geq 0)$, unless the signal or bank closure reveal otherwise.

If and when the public learns that the bank is insolvent it imposes a punitive cost of $x>0$ on the government, which could be an electoral loss or a mass demonstration, for instance. We do not explicitly model why the public takes this action against the government. One interpretation is that when the public feels the financial pain associated with the bank's insolvency, it obtains an intrinsic value from punishing the government, to which it had delegated the task of financial stability.

\footnotetext{
${ }^{13}$ The full expression for these expected costs in integral notation can be found in the proof of Lemma 5.

${ }^{14}$ We do not model here why the bank should exist, from a social perspective. The implicit assumption is that the bank performs a critical function (e.g., in the payment system or in credit provision). An extension within the online appendix makes this explicit.
} 
Examples that financial sector bailouts can impose large tax burdens abound, including for example in countries that had pre-funded deposit insurance systems in place before the Global Financial Crisis (International Association of Deposit Insurers, 2009), but which turned out to be insufficient when the crisis came. Electoral losses for incumbent governments following on financial crises are similarly prevalent, including in the aftermath of the Global Financial Crisis. Indeed, Funke et al. (2016) document 140 years of political turbulence in the aftermath of financial crises.

Overall, the public has a known reaction function rather than an explicit optimization problem in our model. The bank and the government both solve optimization problems, where they consider the public's reaction.

\subsection{The government}

We consider a single policy maker, the government, which represents the public's interests. That is, the government does not suffer from an agency bias that could, for instance, make it susceptible to lobbying by the bank. Indeed, the government does not weigh the bank's profits at all, since bank owners are not counted as part of the public. The fact that the government can end up playing along with the bank even if it cares nothing for the interests of bank owners, is an important outcome. The public's blindness about the financial sector drives the distortions to the government's decision making, which ultimately harm the public itself. The government could, in principle, resolve the information asymmetry by revealing $r$, but when the bank's solvency outcome is realized, the government has an incentive to prevent its revelation, if negative. The government may therefore wish to join the bank's gamble for resurrection, which, if successful, ensures that the public never learns about the bank's insolvency, and therefore does not take punitive action against the government.

The government's loss function is of the form $E[\min \{$ Bank returns, 0$\}-x]$, where the size of $x$ determines how sensitive the government is to the whims of a poorly informed public. If $x \rightarrow 0$, then the very inability of the public to punish the government ensures that the government always maximizes the public's welfare. It is $x>0$ that brings about the connection between the informational problems of the public and the distorted incentives of the government. Indeed, going forward, it proves useful to define the term $x(1-\theta)$ as "the extent to which the government is subject to pressure from a poorly informed public".

In the baseline model, the government possesses a single binary tool, $l$ : legislation about gambles for resurrection by the bank. The government can decide to forbid such gambles, a policy that can be interpreted as the implementation of mark-to-market accounting. This accounting practice forces the bank to immediately recognize the losses to its assets, in line with the deterioration of their market value. Instead, historical cost accounting allows the bank to continue to value assets according to their book value, unless they are sold. During a period that assets lose market value, historical cost accounting buys the bank time, which in our setting translates into the possibility to gamble for resurrection.

Mark-to-market accounting here provides the government with a tool that can prevent gambles for resurrection, as the insolvent $(r<0)$ bank is directly recognized as such and forced to shut 
down. However, the government's desire to veil bank insolvency from the public means that it could opt for historical cost accounting. We let $l=\{$ Allow $\}$ represent historical cost accounting (which "allows" gambles to occur) and $l=\{$ Forbid $\}$ represent mark-to-market accounting (which effectively "forbids" gambles by an insolvent bank). The payoff structure that the government maximizes with this policy is shown in Section 2.4, which defines the payoffs to the different players at various stages of the game.

The government initially legislates before the bank decides on its risk profile. In addition, the government has a probability of being able to change its mind (i.e., rescinding mark-to-market accounting rules in favor of historical cost accounting or vice versa) after bank risk has already materialized. With probability $\lambda \in(0,1)$ the government's second decision stage (i.e., after $r$ is drawn) exists, and with probability $(1-\lambda)$ this stage does not exist. This can be seen as uncertainty about how quickly financial sector developments unfold. Legislating is a slow process in practice, and the government can sometimes find itself behind the curve.

A high $\lambda$ thus represents agile legislation, but agility is a mixed blessing when time consistency matters. Agility can help the government at the moment that it wishes to make a change, but as seen from the government's initial decision stage, it means a less time consistent tool. In the limit case of $\lambda \rightarrow 1$, the government's initial legislation becomes moot, because it can change its mind later in case the bank becomes insolvent.

The government's incentive to allow the bank to gamble for resurrection increases when $r<0$ is a reality. Before the bank's return is drawn, the government sees bank insolvency as only a possibility. Once that possibility becomes reality, the only way to avoid the imposition of $x$ by the public is to allow the bank to gamble. Therefore, the government's legislative incentives suffer from time inconsistency, and $\lambda$ parameterizes the degree of this time inconsistency. In the limit case of $\lambda \rightarrow 0$, once the government makes its initial decision, its hands are fully tied, and the time consistency problem vanishes.

The government's tool to contain bank risk is not ideal. Legislating against future gambles does reduce the bank's incentive to choose the bad project, because if that project fails and if the government cannot or does not want to change its mind, then the bank gets no second chance to return to profit. However, an ideal regulatory tool would target the bank's initial risk choice, $\rho$, in such a way that the bank would always choose $\rho=0$, and this would overcome the tradeoffs in the model, as shown in (a limit case of) the extension in Section 5. However, a regulatory tool that can contain but not fully negate perverse incentives among banks, arguably corresponds well to the reality of financial stability policy. Alternative, but still imperfect, regulatory tools are considered in Sections 4 and 5.

\subsection{Timing of the game}

The actions and the payoffs described in Sections 2.1-2.3 make up a game that consists of seven stages. Figure 1 provides an overview of these, where uncertain outcomes are represented by a striped boxes. The formal definition of the stages is: 
Figure 1: The timing of the game

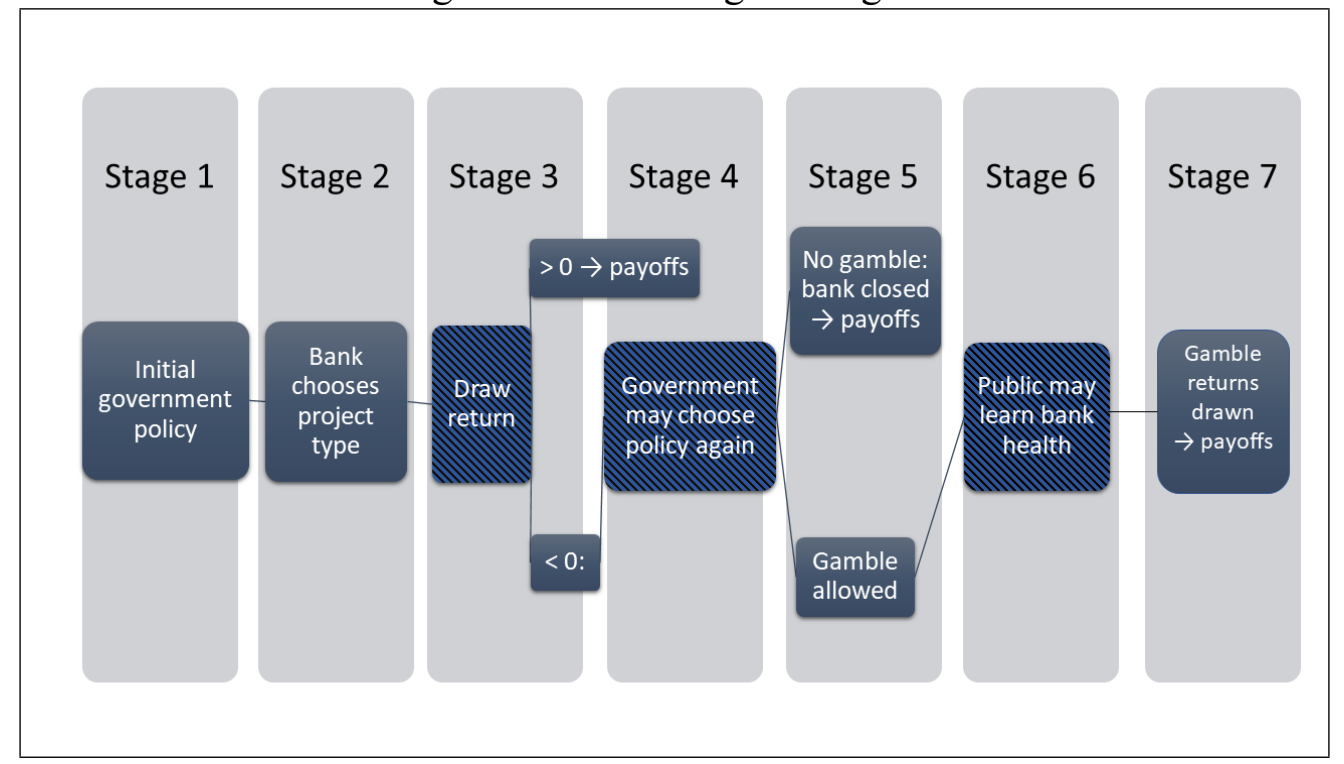

Stage 1 The government determines $l$.

Stage 2 The bank chooses $\rho$.

Stage $3 r$ is drawn. If $r>0$ : the game ends with payoffs $r, 0,0$ for, respectively, the bank, the public and the government. If $r<0$ : the game continues.

Stage 4 With probability $\lambda$ this stage occurs, and the government can once more determine $l$.

Stage 5 If $l=\{$ Forbid $\}$, then the banks shuts down, the public is repaid its deposits, with the government's deposit insurance covering the shortfall, while the public imposes $x$ on the government. If $l=\{$ Allow $\}$, then the game continues.

Stage 6 With probability $\theta$ the public learns that $r<0$, and imposes $x$ on the government.

Stage 7 The bank gambles. With probability $g$ the gamble succeeds, then payoffs are $(r+\alpha+\beta)$, 0 for, respectively, the bank and the public, while the government's payoff is either 0 or $-x$, depending on the outcome of Stage 6. If the gamble fails, then payoffs are $0,(r-\alpha-\beta)$, $(r-\alpha-\beta-x)$ for, respectively, the bank, the public and the government.

\section{Outcomes of the baseline model}

The decision stages of the game are Stage 4, Stage 2, and Stage 1. We solve these by backward induction. 
Lemma 3 If the government gains the opportunity to legislate at Stage 4, then its policy is to set $l=\{$ Forbid $\}$ if and only if

$$
x(1-\theta)<r+(\alpha+\beta) \frac{1-g}{g}
$$

Proof. On page 25.

From (14) we see that at Stage 4 the government will forbid gambles when $x(1-\theta)$ is smaller than a given threshold, and that threshold is larger than zero. ${ }^{15}$ This implies that for $x \rightarrow 0$, the government always forbids gambles at this stage. When rid of political pressure, the government purely weighs the public's well-being rather than the public's knowledge, and therefore prevents the bank from destroying expected project value with its gamble. Similarly, for $\theta \rightarrow 1$ the government's incentive to forbear disappears, because there is no scope to keep the public in the dark about insolvency. Next, we solve for the decisions of the bank at Stage 2 and the government at Stage 1:

Lemma 4 The bank's Stage 2 decision depends on the government's Stage 1 decision. If $l=$ $\{$ Allow $\}$ at Stage 1, then the bank's optimal policy is

$$
\rho=\left\{\begin{array}{c}
1 \text { if } m<\mathbf{m}_{A} \\
0 \text { otherwise }
\end{array}\right.
$$

whereas if $l=\{$ Forbid $\}$ at Stage 1, then the bank optimally sets

$$
\rho=\left\{\begin{array}{c}
1 \text { if } m<\mathbf{m}_{F} \\
0 \text { otherwise }
\end{array}\right.
$$

where $\underline{m}<\mathbf{m}_{F}<\mathbf{m}_{A}<\bar{m}$. Expressions for $\mathbf{m}_{A}$ and $\mathbf{m}_{F}$ can be found in (31) and (33).

Proof. On page 25.

Lemma 5 At Stage 1, the government's optimal policy is $l=\{$ Allow $\}$ if

$$
m<\mathbf{m}_{F} \text { and } x(1-\theta)>\frac{1}{2} m+\frac{(\alpha+\beta)(2-3 g)}{2 g}
$$

and $l=\{$ Forbid $\}$ otherwise. An equivalent way to express (17) is

$$
m<\min \left\{\mathbf{m}_{F}, 3(\alpha+\beta)+2\left(x(1-\theta)-\frac{\alpha+\beta}{g}\right)\right\}
$$

\footnotetext{
${ }^{15}$ From (1)-(6), the lower bound on $r$ is $-(\alpha+b)$ and therefore given $g<\frac{1}{2}$ the right-hand side in (14) is positive.
} 
Proof. On page 26.

The conditions for government action as expressed in (17) and (18), represent two ways of looking at the government's optimal policy. The (second) condition in (17) says that the government allows gambles when it faces too much pressure from a poorly informed public (i.e., $x(1-\theta)$ is large enough). The condition in (18) tells us that at Stage 1 the government fails to act against gambles when $m$ is too low. Therefore, precisely when the banks' incentives to engage in detrimental risk taking are at their worst, because the bank has little skin in the game, the government also has the strongest incentives to play along and let the bank get away with a play on the public safety net.

Lemma 5 gives us the foundation to derive the key result in Proposition 1.

Proposition 1 The time inconsistency of the government's tool, $\lambda$, interacts non-monotonically with the government's optimal policy. In (17), both $\frac{\partial \mathbf{m}_{F}}{\partial \lambda}<0$ and $\frac{\partial \mathbf{m}_{F}}{\partial \lambda}>0$ are possible. The expression for $\frac{\partial \mathbf{m}_{F}}{\partial \lambda}$, shown in (38), can be split into two terms: one (39) which is strictly positive, and derives from the fact that a less time consistent regulatory tool has less effect on the bank's risk taking incentives; the other (40) is strictly negative and represents the impact of increased time inconsistency on the government's initial desire to tie its own hands. It can be shown numerically that, within the allowed parameter space, either effect can dominate.

Proof. On page 27.

Proposition 1 brings in the government's time consistency problem. When $\lambda \rightarrow 0$ and the government's initial legislation can never be changed, the government's ability to influence the bank's behavior is maximized. The government can now decide whether to make the bank face the optimization problem in Lemma 1, where gambles never exist, or Lemma 2, where the option to gamble always exists. Possession of a more effective tool (lower $\lambda$ ) can entice the government to use it.

However, the government is not only playing against the bank; it is also playing against its future self. This game between the Stage 1 government and the Stage 4 government emanates from the evolution of the game tree. If there is a Stage 4 at all, this means that the bank has become insolvent, something that was only a possibility at Stage 1. Bank insolvency makes the government more lenient, as it hopes to hide insolvency from the public's eye. The government at Stage 1 dislikes the prospect of its more lenient future self. Therefore, a less time consistent tool can make the Stage 1 government more disposed to forbid future gambles, in an attempt to compensate in the present for the probability that it will be allowed to change its mind in the future.

Overall, Proposition 1 shows that the range of values of $m$ for which the government allows gambles to occur, can either expand or contract when $\lambda$ increases. That is, the relationship between time consistency and the incentive of the government to forbear is intricate, and possessing a more time consistent tool is not a cure-all for socially optimal regulation. Depending on other parameters, time consistency can "backfire" and make a government less inclined to protect the public's interest. 


\section{Conditioning policy on bank solvency}

In the baseline model the government possesses a binary tool. How are the model's outcomes affected when the policy menu becomes more sophisticated, and the government can legislate a mapping between $r$ and whether or not the bank is allowed to gamble for resurrection? For instance, the government could mandate mark-to-market accounting under normal circumstances, but with a clause for times of exceptional distress, defined by a threshold of $r$, during which the bank may forgo on marking down its assets and recognizing insolvency.

Instead of a two-stage government decision process, this extension models a single decision stage at which the government determines a policy mapping, $l(r)$, with

$$
l(r)=\left\{\begin{array}{l}
\{\text { Allow }\} \text { if } r \in S \\
\{\text { Forbid }\} \text { if } r \notin S
\end{array}\right.
$$

The government's task is now to maximize its expected payoff to its choice of $S$, which is the set of values of $r$ for which the bank will be allowed to gamble. In the timing of the game shown in Section 2.4, Stage 1 now becomes: the government determines $l(r)$. Stages 2 and 3 are unchanged, Stage 4 is cut, and Stages 5, 6, and 7 remain identical but become, respectively, Stages 4,5 , and 6 .

The announcement of a policy mapping can affect the imperfect information environment assumed for the public. In the baseline model, the public's prior is that the bank is solvent $(r \geq 0)$, unless the signal or bank closure reveal otherwise. Regulatory policy does not affect this prior, which we believe finds a counterpart in reality, where usually the public would be oblivious to accounting methods. More generally, forms of regulatory forbearance have frequently been implemented without causing public concern. But if the policy maker announces that a certain type of policy will only apply if the bank is insolvent, then the public could make inferences on bank solvency from observed policy actions, and forbearance ceases to work as the government intended. To address this, we now give the government an additional policy option: over desired ranges of $r$, it can play a mixed strategy. For instance, for values of $r$ for which the government is indifferent about the chosen policy, a coin toss determines whether mark-to-market or historical cost accounting applies. As seen in Proposition 2, this suffices to prevent the public revelation of bank solvency based on government actions. Including elements of a mixed strategy is optimal for the government in this case, because without it, the government could not try and hide bank insolvency from the public when it wants to.

Proposition 2 When the government is able to condition its legislation on future bank returns, its optimal policy profile becomes: if $r<0$, set

$$
l(r)=\left\{\begin{array}{c}
\{\text { Allow }\} \text { if } r<x(1-\theta)-(\alpha+\beta) \frac{1-g}{g} \\
\{\text { Forbid }\} \text { otherwise }
\end{array}\right.
$$

while the government plays a mixed strategy when $r \geq 0$.

Proof. On page 27. 
Proposition 2 shows that the government only allows gambles when the bank is sufficiently insolvent. ${ }^{16}$ This result brings together several features of the model. First, when the political pressure from a poorly informed public becomes small enough, the government always forbids the bank's gambles. That is, when either the public is perfectly informed and $\theta \rightarrow 1$ or when the government is indifferent to public pressure and $x \rightarrow 0$, we have that $x(1-\theta) \rightarrow 0$, in which case the condition in (20) never holds. ${ }^{17}$

However, when the government feels enough pressure from a poorly informed public, then the extent of insolvency affects the government's decision. If the bank is only barely insolvent ( $r$ just below zero) then the full upside of the gamble accrues to the bank only. The worse is the bank's position to begin with (the more negative is $r$ ), the more upside there is between $r$ and 0 , and this upside accrues to the public and therefore also the government. Of course, the public always bears the full burden of the downside of the gamble, which is why a government unconcerned with political pressure would never allow such a gamble. But once political pressure matters, a greater participation in the upside of the gamble is an additional sweetener, which can tip the balance.

\section{Targeting the bank's risk profile}

Thus far, the analysis has centered on a policy tool that can affect gambles for resurrection, and thereby also indirectly impact the bank's initial risk profile choice. But what if, aside from the choice between mark-to-market and historical value accounting, the government also possessed a more direct tool to target the bank's initial risk profile? Would the government optimally use the different tools as substitutes or as complements? Would the ability to directly target the bank's project choice alter Proposition 1?

In this section, in addition to regulatory policy in the form of $l$, the government also uses a risk cap, $\bar{\rho}$. This can be considered a shorthand form for a risk-weighted capital requirement. That is, qualitatively, the key is to provide the government with a means to directly target the asset risk choice, $\rho$. To retain tractability, we choose to model this in the simplest form, with a cap on the risk that the bank is allowed to take, rather than adding the layer of bank capital and an optimization over the bank's liability side.

The imposition of the risk cap is subject to two frictions. First, there is a chance that the bank finds ways to arbitrage the regulation. We model this with a probability, $\phi \in(0,1)$, that the regulation is successful at binding bank risk. That is, with probability $\phi, \bar{\rho}$ binds $\rho$, whereas with probability $(1-\phi)$ the bank succeeds at arbitraging the risk cap, and is free to set $\rho$ as it pleases. The baseline model is contained in the case $\phi \rightarrow 0$, as the risk cap becomes completely ineffec-

\footnotetext{
${ }^{16}$ This discussion is for the $r<0$ case. The mixed strategy for $r \geq 0$ has no effect on gambles, because the bank does not gamble when it is solvent.

${ }^{17}$ This is so, because the condition in (20) then becomes $r<-(\alpha+\beta) \frac{1-g}{g}$, while the lower bound on $r$ is $-(\alpha+\beta)$, per (1)-(3) and $m>0$. Moreover, by $g<\frac{1}{2}$ we have that $\frac{1-g}{g}>1$ and therefore $-(\alpha+\beta) \frac{1-g}{g}<$ $-(\alpha+\beta)$ and hence below the lower bound on $r$.
} 
tive and only legislation $l$ remains as government policy. Instead, $\phi \rightarrow 1$ represents the case of a "perfect" regulatory tool, which gives the government full control over the bank's risk profile.

The second friction is that a forced adjustment of its risk profile is costly to the bank. This relates to the notion that a bank owns long term assets of limited liquidity, and therefore faces costs associated with changing its portfolio. When the bank chooses its risk profile, it does not yet know whether it will succeed at finding opportunities to circumvent $\bar{\rho}$. If the bank chooses a value of $\rho$ above $\bar{\rho}$ and is subsequently forced to adjust down, then the cost of doing so is $\eta(\rho-\bar{\rho})$, where $\eta \in(0,1)$. Absent such a friction (i.e., if $\eta=0)$, the bank sees no peril to ignoring the risk cap: it would first try to set its preferred risk profile, only adjusting to $\bar{\rho}$ when regulatory arbitrage fails. The timing of the game is now as follows:

Stage 1 The government chooses both the bank risk cap, $\bar{\rho}$, and the legislation on gambles, $l$.

Stage 2 The bank chooses $\rho$.

Stage 3 The bank attempts regulatory arbitrage: with probability $\phi, \bar{\rho}$ successfully constrains $\rho$. With probability $(1-\phi), \bar{\rho}$ is reset to $\rho$ (i.e., arbitrage is successful and $(\rho-\bar{\rho})=0$ ).

Stage $4 r$ is drawn. If $r>0$ : the game ends with payoffs $r-\eta(\rho-\bar{\rho}), 0,0$ for, respectively, the bank, the public and the government. If $r<0$ : the game continues.

Stage 5 With probability $\lambda$ this stage occurs, and the government can once more determine $l$.

Stage 6 If $l=\{$ Forbid $\}$ : the game ends with Stage 4 payoffs. If $l=\{$ Allow $\}$ : the game continues.

Stage 7 With probability $\theta$ the public learns that $r<0$, and imposes $x$ on the government.

Stage 8 Gamble: Payoffs $-\eta(\rho-\bar{\rho}),(r-\alpha-\beta),(r-\alpha-\beta-x)$ for, respectively, the bank, the public and the government if the gamble fails (with probability $1-g)$. And $(r+\alpha+\beta)-$ $\eta(\rho-\bar{\rho}), 0,\{0,-x\}$ (depending on Stage 7) if the gamble succeeds (with probability $g$ ).

Solving by backward induction, the government's Stage 5 optimization problem is unchanged compared to (Stage 4 in) the baseline model. Therefore, Lemma 3 continues to describe optimization at this stage. For Stage 2 and Stage 1 optimization we now obtain:

Lemma 6 At Stage 2, the bank's optimal policy is

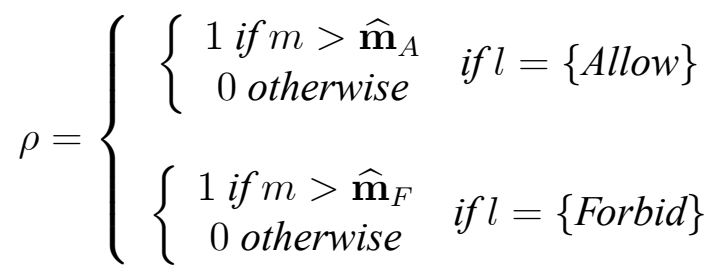

where $\widehat{\mathbf{m}}_{F}<\widehat{\mathbf{m}}_{A}, \widehat{\mathbf{m}}_{A}<\mathbf{m}_{A}$ and $\widehat{\mathbf{m}}_{F}<\mathbf{m}_{F}$. Here, $\widehat{\mathbf{m}}_{A} \rightarrow \mathbf{m}_{A}$ and $\widehat{\mathbf{m}}_{F} \rightarrow \mathbf{m}_{F}$ (recovering the baseline model) for $\phi \rightarrow 0$. Instead, for $\phi \rightarrow 1$ the bad project is never chosen. 
Proof. On page 28.

Lemma 7 At Stage 1, the government's optimal policy is $\bar{\rho}=0$, combined with $l=\{$ Allow $\}$ if

$$
m<\widehat{\mathbf{m}}_{F} \text { and } x(1-\theta)>\frac{1}{2} m+\frac{(\alpha+\beta)(2-3 g)}{2 g}
$$

and $l=\{$ Forbid $\}$ otherwise.

Proof. On page 28.

We first note that possessing a perfect regulatory tool always entails a first-best outcome:

Remark $1 \phi \rightarrow 1$ implies $\rho=\bar{\rho}=0$ and therefore the socially optimal outcome with payoffs $(m, 0,0)$ for, respectively, the bank, the public and the government.

Moreover, building on these Lemmas, we can derive the key result of this section:

Proposition 3 Proposition 1 remains valid in this extension (i.e., both $\frac{\partial \widehat{\mathbf{m}}_{F}}{\partial \lambda}<0$ and $\frac{\partial \widehat{\mathbf{m}}_{F}}{\partial \lambda}>0$ are possible). Moreover, the government optimally uses its two policy tools, $\bar{\rho}$ and $l$, as complements rather than substitutes: with the risk cap in hand, the government forbids gambles using l over a larger range of possible values of $m$ than it does without the risk cap.

Proof. On page 29.

The continued prevalence of the time consistency problem is highlighted by the fact that the government uses its two tools as complements. A priori, when a second tool becomes available for the same target, one might expect a policy maker to optimally use the tools as substitutes, so that applying more of the one goes together with applying less of the other. But the impact of time inconsistency runs counter to this intuition. A greater likelihood of being bound by the risk cap, makes the bank less inclined to take risk and, even if the bank still wants to choose the bad project, it sometimes cannot do so, because its regulatory arbitrage fails. This means that at Stage 1, the government knows that bank failure happens less often. That, in turn, reduces the attraction of joining in the bank's future gamble, because the need to cover up bank insolvency from the public is less likely to arise. The government therefore becomes more inclined to stop the gambles and opt for mark-to-market regulation.

\section{Conclusion}

The buffers that the banking sector built up after the Global Financial Crisis have largely held up during this pandemic, aided by deferred loss recognition in many countries, although significant 
risks and vulnerabilities remain (International Monetary Fund, 2020). If bank insolvencies do occur, will regulators reveal these?

The incentive to forbear can be powerful when bad news imposes losses on the policy maker, while there is a chance that muddling through will succeed, and the public never learns of the bad news. Muddling through does not necessarily mean that the policy maker is indifferent to the public. Indeed, when information asymmetries abound, caring about what the public thinks can be the very reason to try and keep it in the dark, as entailed by our model.

In this paper, a microfounded desire to muddle through meets policy credibility. This interaction between the political economy and time consistency problems of financial regulation, each separately well-established in the literature, is the paper's key novelty. We explore this interaction by modeling probabilistic decision stages, which allow us to vary the degree of time consistency. The outcome is that in the presence of political motivations, policy credibility is a double-edged sword.

Which distorted incentives is the policy maker keenest to influence: those of the bank, or its own? A more credible tool gives the policy maker a stronger ax to wield against the incentives of the financial sector to take on excessive risk. This added potency can raise the policy maker's incentive to act. However, a less credible tool increases the urgency for the policy maker to be tough up front, precisely because the tool is weakened by the policy maker's own future incentives to forbear. Overall, time consistency and incentives to regulate are bound by an intricate relation, and more time consistent policy tools can push those incentives either way, a result that holds up in various alternative setups considered in extensions.

In our model the pressure that policy makers feel from a public that has only a crude insight into the financial sector, is the central impediment to welfare maximization. This impediment actually consists or two separate obstacles, which in the preceding sentence are represented by the words "pressure" and "crude insight". If the policy maker would focus only on a financial stability target, come public storm or sunshine, then the public's informational problems lose their bite. Financial regulators could be granted more operational and financial independence, to help detach their incentives from political cycles.

Alternatively, it is the public's lack of information about the financial sector that could be tackled politically (e.g., the electorate putting in place politicians who mandate regulatory transparency at all times, including when insolvency actually occurs) and possibly through increased financial literacy. When faced with a well-informed public, muddling through loses its appeal to the policy maker. 


\section{References}

Acharya, V. V., Eisert, T., Eufinger, C., and Hirsch, C. (2019). Whatever It Takes: The Real Effects of Unconventional Monetary Policy. Review of Financial Studies, 32(9):3366-3411.

Adrian, T. and Shin, H. S. (2010). Liquidity and Leverage. Journal of Financial Intermediation, 19(3):418- 437.

Agca, S., Igan, D., Li, F., and Mishra, P. (2019). Doing More for Less? New Evidence on Lobbying and Government Contracts. IMF Working Papers 19/172.

Agur, I. (2014). Bank Risk Within and Across Equilibria. Journal of Banking and Finance, $48: 322-333$.

Agur, I. and Sharma, S. (2014). Rules, Discretion, and Macro-Prudential Policy. In Huang, R. H. and Schoenmaker, D., editors, Institutional Structure of Financial Regulation: Theories and International Experiences. Routledge.

Allen, F. and Carletti, E. (2008). Mark-to-Market Accounting and Liquidity Pricing. Journal of Accounting and Economics, 45(2):358 - 378.

Almasi, P., Dagher, J., and Prato, C. (2018). Regulatory Cycles: A Political Economy Model. SSRN Electronic Journal.

Basel Committee on Banking Supervision (2020). Measures to Reflect the Impact of COVID-19. BCBS publication.

Behn, M., Haselmann, R., Kick, T., and Vig, V. (2015). The Political Economy of Bank Bailouts. IMFS Working Paper Series 86.

Benmelech, E. and Moskowitz, T. J. (2010). The Political Economy of Financial Regulation: Evidence from U.S. State Usury Laws in the 19th Century. Journal of Finance, 65(3):10291073.

Bergant, K. and Kockerols, T. (2020). Forbearance Patterns in the Post-Crisis Period. IMF Working Papers 20/140.

Bianchi, J. and Mendoza, E. G. (2018). Optimal Time-Consistent Macroprudential Policy. Journal of Political Economy, 126(2):588-634.

Bond, P. and Glode, V. (2014). The Labor Market for Bankers and Regulators. Review of Financial Studies, 27(9):2539-2579.

Bonfim, D., Cerqueiro, G., Degryse, H., and Ongena, S. (2020). On-Site Inspecting Zombie Lending. CEPR Discussion Papers 14754.

Boot, A. and Thakor, A. (1993). Self-Interested Bank Regulation. American Economic Review, 83(2):206-12. 
Brown, C. O. and Dinç, I. S. (2005). The Politics of Bank Failures: Evidence from Emerging Markets. The Quarterly Journal of Economics, 120(4):1413-1444.

Caballero, R. J., Hoshi, T., and Kashyap, A. K. (2008). Zombie Lending and Depressed Restructuring in Japan. American Economic Review, 98(5):1943-77.

Chang, R. (2007). Financial Crises and Political Crises. Journal of Monetary Economics, 54(8):2409- 2420.

Colliard, J.-E. and Gromb, D. (2018). Financial Restructuring and Resolution of Banks. HAL Working Papers 01933873.

Dagher, J. (2018). Regulatory Cycles: Revisiting the Political Economy of Financial Crises. IMF Working Papers 18/8.

Dell’Ariccia, G., Peria, M. S. M., Igan, D. O., Awadzi, E. A., Dobler, M. C., and Sandri, D. (2018). Trade-offs in Bank Resolution. IMF Staff Discussion Notes 18/02.

Diamond, D. W. and Rajan, R. G. (2012). Illiquid Banks, Financial Stability, and Interest Rate Policy. Journal of Political Economy, 120(3):552-591.

Edge, R. M. and Liang, J. N. (2019). New Financial Stability Governance Structures and Central Banks. Federal Reserve Board, Finance and Economics Discussion Series 2019-019.

Ellul, A., Jotikasthira, C., Lundblad, C. T., and Wang, Y. (2014). Mark-to-Market Accounting and Systemic Risk: Evidence from the Insurance Iindustry. Economic Policy, 29(78):297-341.

Ennis, H. M. and Keister, T. (2010). Banking Panics and Policy Responses. Journal of Monetary Economics, 57(4):404 - 419.

Farhi, E. and Tirole, J. (2012). Collective Moral Hazard, Maturity Mismatch, and Systemic Bailouts. American Economic Review, 102(1):60-93.

Farhi, E. and Werning, I. (2016). A Theory of Macroprudential Policies in the Presence of Nominal Rigidities. Econometrica, 84(5):1645-1704.

Fraccaroli, N., Sowerbutts, R., and Whitworth, A. (2020). Does Regulatory and Supervisory Independence Affect Financial Stability? Bank of England Staff Working Paper 893.

Funke, M., Schularick, M., and Trebesch, C. (2016). Going to Extremes: Politics after Financial Crises, 1870 - 2014. European Economic Review, 88:227 - 260.

Gersbach, H. and Papageorgiou, S. (2019). On Banking Regulation and Lobbying. CER-ETH Working Paper Series 19/308.

Goodhart, C. and Schoenmaker, D. (1995). Should the Functions of Monetary Policy and Banking Supervision Be Separated? Oxford Economic Papers, 47(4):539-560.

Hakenes, H. and Schnabel, I. (2014). Regulatory Capture by Sophistication. CEPR Discussion Papers 10100. 
Herrera, H., Ordonez, G., and Trebesch, C. (2020). Political Booms, Financial Crises. Journal of Political Economy, 128(2):507-543.

Igan, D. and Lambert, T. (2019). Bank Lobbying: Regulatory Capture and Beyond. IMF Working Papers 19/171.

Igan, D., Lambert, T., Wagner, W., and Zhang, Q. (2017). Winning Connections? Special Interests and the Sale of Failed Banks. IMF Working Papers 17/262.

Igan, D. and Mishra, P. (2012). The Power of K: Politically-Targeted Activities, Connections and the Financial System. Journal of Financial Transformation, 35:147-158.

Igan, D. and Mishra, P. (2014). Wall Street, Capitol Hill, and K Street: Political Influence and Financial Regulation. Journal of Law and Economics, 57(4):1063-1084.

Igan, D., Mishra, P., and Tressel, T. (2012). A Fistful of Dollars: Lobbying and the Financial Crisis. NBER Macroeconomics Annual, 26(1):195-230.

International Association of Deposit Insurers (2009). Funding of Deposit Insurance Systems. Report by by the Research and Guidance Committee of IADI.

International Monetary Fund (2020). Bank Capital: COVID-19 Challenges and Policy Responses. Oct. 2020 Global Financial Stability Report, Ch. 4.

Ioannidou, V. P. (2005). Does Monetary Policy Affect the Central Bank's Role in Bank Supervision? Journal of Financial Intermediation, 14(1):58 - 85.

Jeanne, O. and Korinek, A. (2019). Managing Credit Booms and Busts: A Pigouvian Taxation Approach. Journal of Monetary Economics, 107:2 - 17.

Jeanne, O. and Korinek, A. (2020). Macroprudential Regulation Versus Mopping up After the Crash. The Review of Economic Studies, 87(3):1470-1497.

Keeley, M. C. (1990). Deposit Insurance, Risk, and Market Power in Banking. American Economic Review, 80(5):1183-1200.

Keister, T. (2016). Bailouts and Financial Fragility. Review of Economic Studies, 83(2):704-736.

Keister, T. and Mitkov, Y. (2019). Bailouts, Bail-ins and Banking Crises. Mimeo.

Kroszner, R. S. and Strahan, P. E. (1999). What Drives Deregulation? Economics and Politics of the Relaxation of Bank Branching Restrictions. The Quarterly Journal of Economics, 114(4):1437-1467.

Liu, W.-M. and Ngo, P. T. (2014). Elections, Political Competition and Bank Failure. Journal of Financial Economics, 112(2):251 - 268.

Lucca, D., Seru, A., and Trebbi, F. (2014). The Revolving Door and Worker Flows in Banking Regulation. Journal of Monetary Economics, 65:17 - 32. 
Martynova, N., Perotti, E. C., and Suarez, J. (2019). Bank Capital Forbearance. CEPR Discussion Papers 13617.

Masciandaro, D. and Passarelli, F. (2013). Financial Systemic Risk: Taxation or Regulation? Journal of Banking and Finance, 37(2):587 - 596.

Mian, A., Sufi, A., and Trebbi, F. (2010). The Political Economy of the US Mortgage Default Crisis. American Economic Review, 100(5):1967-98.

Mian, A., Sufi, A., and Trebbi, F. (2013). The Political Economy of the Subprime Mortgage Credit Expansion. Quarterly Journal of Political Science, 8(4):373-408.

Morrison, A. D. and White, L. (2013). Reputational Contagion and Optimal Regulatory Forbearance. Journal of Financial Economics, 110(3):642 - 658.

Müller, K. (2019). Electoral Cycles in Macroprudential Regulation. SSRN Electronic Journal.

Myerson, R. B. (2014). Rethinking the Principles of Bank Regulation: A Review of Admati and Hellwig's The Bankers' New Clothes. Journal of Economic Literature, 52(1):197-210.

Nunez, S. and Rosenthal, H. (2004). Bankruptcy Reform in Congress: Creditors, Committees, Ideology, and Floor Voting in the Legislative Process. The Journal of Law, Economics, and Organization, 20(2):527-557.

Peek, J. and Rosengren, E. S. (2005). Unnatural Selection: Perverse Incentives and the Misallocation of Credit in Japan. American Economic Review, 95(4):1144-1166.

Rajan, R. G. and Zingales, L. (2003). The Great Reversals: The Politics of Financial Development in the Twentieth Century. Journal of Financial Economics, 69(1):5 - 50.

Rola-Janicka, M. (2019). The Political Economy of Prudential Regulation. Mimeo.

Romer, T. and Weingast, B. R. (1991). Political Foundations of the Thrift Debacle. In Politics and Economics in the Eighties, NBER Chapters, pages 175-214. NBER.

Shapiro, J. and Skeie, D. (2015). Information Management in Banking Crises. Review of Financial Studies, 28(8):2322-2363.

Sharma, S. and Fullenkamp, C. (2012). Good Financial Regulation: Changing the Process is Crucial. SSRN Electronic Journal.

Shive, S. A. and Forster, M. M. (2016). The Revolving Door for Financial Regulators. Review of Finance, 21(4):1445-1484.

Shleifer, A. and Vishny, R. W. (2010). Unstable Banking. Journal of Financial Economics, 97(3):306-318.

Stratmann, T. (2002). Can Special Interests Buy Congressional Votes? Evidence from Financial Services Legislation. Journal of Law and Economics, 45:345-73. 
Tressel, T. and Verdier, T. (2014). Optimal Prudential Regulation of Banks and the Political Economy of Supervision. IMF Working Papers 14/90.

Veltrop, D. and de Haan, J. (2014). I Just Cannot Get You Out of My Head: Regulatory Capture of Financial Sector Supervisors. Academy of Management Proceedings, 2014(1).

Walther, A. and White, L. (2020). Rules versus Discretion in Bank Resolution. The Review of Financial Studies, in press: doi.org/10.1093/rfs/hhaa032. 


\section{Appendix: Proofs}

Derivations in these proofs are conducted in a Mathematica file that is available on request.

Proof of Lemma 1. Using (1), (2), and (8), we can solve (7) to ${ }^{18}$

$$
E[\Pi]=\frac{(m+(\beta-\alpha) \rho)^{2}}{4 \beta \rho}
$$

The convex form of the expression for $E[\Pi]$ can be seen directly from (23), given $\beta>\alpha$ from (4). We also verify numerically that for all parameter values allowed by (4)-(6), we have $\frac{\partial^{2} E[\Pi]}{\partial \rho^{2}}>$ 0 .

This convexity implies that corners are always optimal, and therefore the bank chooses either the corner of the safest, $\rho=0$ profile or that of the riskiest, $\rho=1$. The expected return when $\rho=0$ is $m$, while from (7) expected return when $\rho=1$ is $\frac{(m+\beta-\alpha)^{2}}{4 \beta}$. Therefore $\underline{m}$ is the solution to

$$
m=\frac{(m+\beta-\alpha)^{2}}{4 \beta}
$$

which gives the solution in (10), as well as a second solution, $\underline{m}=\alpha+\beta+2 \sqrt{\alpha \beta}$, which can however be excluded by $m<\alpha+\beta$ from (6).

Proof of Lemma 2. Rewriting from (11), the bank's optimization problem is given by $\max _{\rho}\{E[\Pi]\}=$

$$
\max _{\rho}\left\{\int_{0}^{\mu+w} r f(r) d r+\int_{\mu-w}^{0} g(r+\alpha+\beta) f(r) d r\right\}
$$

where expected profit becomes

$$
E[\Pi]=\left\{\begin{array}{c}
m \text { if } \rho=0 \\
\frac{(m+\beta-\alpha)^{2}-g(m-\alpha-\beta)^{2}+2 g(\alpha+\beta)(\alpha+\beta-m)}{4 \beta} \text { if } \rho=1
\end{array}\right.
$$

and the optimal solution to this is analytically solved to $\rho=1 \Leftrightarrow m<\bar{m}$ where $\bar{m}$ is given by the expression in (13), and $\rho=0 \Leftrightarrow m>\bar{m} .{ }^{19}$ Lastly, $\bar{m}>\underline{m}$ is found numerically from

\footnotetext{
${ }^{18}$ More precisely, the expression in (23) holds when $\rho>0$, because for $\rho \rightarrow 0$ the width of the uniform distribution goes to 0 and the integral in (7) is no longer defined. However, from (1) it can be seen directly that in the limit case of $\rho \rightarrow 0$, the mean return goes to $m$. Simultaneously, the variance goes to 0 for $\rho \rightarrow 0$, by (2). With zero variance, and with a positive mean return (given $m>0$ ), the limited liability option has no value, and therefore the bank's expected return equals the project's mean return, $m$. (6).

${ }^{19} \mathrm{~A}$ second solution is $\bar{m}=\frac{\alpha+\beta+2 \sqrt{\alpha \beta(1-g)+\frac{1}{4}(\alpha+\beta)^{2} g^{2}}}{1-g}$ but this solution can be excluded by $m<\alpha+\beta$ from
} 
$\inf _{\alpha \in\left(0, \frac{1}{2}\right], \beta \in\left(0, \frac{1}{2}\right], g \in\left(0, \frac{1}{2}\right]}(\bar{m}-\underline{m})>0$ (i.e., for all values allowed within the parameterization, $\bar{m}-\underline{m}$ is positive $)^{20}$

Proof of Lemma 3. Following the payoffs in the game stages in Section 2.4, if the government gets to take a second decision at Stage 4, then the government's expected payoff at that stage is

$$
(1-g)(r-(\alpha+\beta)-x)+g(0-\theta x-(1-\theta)(0))=(1-g)(r-\alpha-\beta)-x(1-g+g \theta)
$$

when it sets $l=\{$ Allow $\}$. Instead, if the government sets $l=\{$ Forbid $\}$ then the bank closes and the government has an immediate payoff of

$$
r-x
$$

where we recall that, conditional on being at Stage 4, it must be that $r<0$ and therefore the expressions in both (27) and (28) are negative. The government thus chooses the option that minimizes its losses, which means it forbids the gamble when

$$
r-x>(1-g)(r-\alpha-\beta)-x(1-g+g \theta)
$$

and this can be solved to (14).

Proof of Lemma 4. At Stage 2, the bank solves $\max _{\rho}\{E[\Pi]\}=$

$$
\left\{\begin{array}{c}
\max _{\rho}\left\{\begin{array}{c}
\int_{0}^{m+(\beta-\alpha) \rho} r f(r) d r+(1-\lambda) \int_{m-(\alpha+\beta) \rho}^{0} g(r+\alpha+\beta) f(r) d r \\
+\lambda \int_{m-(\alpha+\beta) \rho}^{x(1-\theta)-(\alpha+\beta)\left(\frac{1-g}{g}\right)} g(r+\alpha+\beta) f(r) d r
\end{array}\right\} \text { if } l=\{\text { Allow }\} \\
\max _{\rho}\left\{\begin{array}{c}
\int_{0}^{m+(\beta-\alpha) \rho} r f(r) d r+(1-\lambda)(0) \\
+\lambda \int_{m-(\alpha+\beta) \rho}^{x(1-\theta)-(\alpha+\beta)\left(\frac{1-g}{g}\right)} g(r+\alpha+\beta) f(r) d r
\end{array}\right\} \text { if } l=\{\text { Forbid }\}
\end{array}\right.
$$

where the integrals can be solved given $f(r)$ from (8). ${ }^{21}$ Following the same steps as in the proofs of Lemma's 1 and 2, this gives bank optimal policy as $\rho=1 \Leftrightarrow m<\mathbf{m}_{A}$ and $\rho=0 \Leftrightarrow m>\mathbf{m}_{A}$ when $l=\{$ Allow $\}$ at Stage 1 , where

$$
\mathbf{m}_{A}=\frac{\alpha+\beta-\beta \sqrt{\frac{\Omega_{A}}{\beta^{2} g}}}{1-g}
$$

\footnotetext{
${ }^{20}$ Note that $\alpha \in\left(0, \frac{1}{2}\right], \beta \in\left(0, \frac{1}{2}\right]$ is stronger than strictly needed (i.e., sufficient but not necessary) since $\beta>\alpha$.

${ }^{21}$ Here the term $x(1-\theta)-(\alpha+\beta)\left(\frac{1-g}{g}\right)$ inside the last integral comes from rewriting the threshold for legislative action by the government in Stage 4 from (14) to $r>x(1-\theta)-(\alpha+\beta)\left(\frac{1-g}{g}\right)$.
} 
where

$$
\begin{aligned}
\Omega_{A}= & (\alpha+\beta)^{2}\left(g^{3}+(1-g)^{2}(3 g-1) \lambda\right)+4 \alpha \beta g(1-g) \\
& +2 \lambda(\alpha+\beta) x(1-\theta) g(1-g)(1-2 g)+\lambda(1-g) g^{2}(1-\theta)^{2} x^{2}
\end{aligned}
$$

whereas if $l=\{$ Forbid $\}$ then bank optimal policy is solved to $\rho=1 \Leftrightarrow m<\mathbf{m}_{F}$ and $\rho=0 \Leftrightarrow$ $m>\mathbf{m}_{F}$ where

$$
\mathbf{m}_{F}=\frac{\alpha+\beta-\beta \sqrt{\frac{\Omega_{F}}{\beta^{2} g}}}{1-g \lambda}
$$

where

$$
\begin{aligned}
\Omega_{F}= & (\alpha+\beta)^{2} \lambda(g(4+\lambda-g(4(1-g) \lambda+3))-1)+4 \alpha \beta g(1-\lambda g) \\
& -g \lambda(1-g \lambda)(\theta-1) x(2(\alpha+\beta)(1-2 g)+g(\theta-1) x)
\end{aligned}
$$

Lastly, $\underline{m}<\mathbf{m}_{F}<\mathbf{m}_{A}<\bar{m}$ can be directly observed from (30) in relation to (7) and (25). First, $\underline{m}$ is derived from maximizing (7). The $l=\{$ Forbid $\}$ case within (30) converges to (7) in the limit case $\lambda \rightarrow 0$. For any $\lambda>0$, (30) has an additional term that is 0 under $\rho=0$ but positive under $\rho=1$, and therefore raises $\mathbf{m}_{F}$ above $\underline{m}$. The same argument, comparing $l=\{$ Allow $\}$ case within (30) to (25) for $\lambda>0$, yields $\mathbf{m}_{A}<\bar{m}$. Similarly, $\mathbf{m}_{F}<\mathbf{m}_{A}$ can be seen directly from (30): they converge in the limit case $\lambda \rightarrow 1$ but for any $\lambda<1$, the $l=\{$ Allow $\}$ case has an additional term that is 0 under $\rho=0$ but positive under $\rho=1$, and therefore raises $\mathbf{m}_{A}$ above $\mathbf{m}_{F}$.

Proof of Lemma 5. The payoff structure of the government at Stage 1, depends on its actions (rows) and on the bank's incentives (columns, which follow the thresholds derived in Lemma 4) as follows:

$$
\begin{array}{cccc} 
& m>\mathbf{m}_{A} & m \in\left(\mathbf{m}_{F}, \mathbf{m}_{A}\right) & m<\mathbf{m}_{F} \\
\text { Allow } & 0 & <0 & (1-\lambda) \int_{\mu-w}^{0}((1-g)(r-\alpha-\beta-x)-g \theta x) f(r) d r+Z \\
\text { Forbid } & 0 & 0 & (1-\lambda) \int_{\mu-w}^{0}(r-x) f(r) d r+Z
\end{array}
$$

Here $Z$ is a term starting with $\lambda$ which represents the expected payoff for the government contingent on being allowed to set policy again at Stage 4 . This $Z$ term therefore does not depend on the Stage 1 action (i.e., it is identical for $l=\{$ Allow $\}$ and $l=\{$ Forbid $\}$ in Stage 1), and is solely determined by the condition in (14). From the matrix above, the only case where $l=\{$ Allow $\}$ dominates $l=\{$ Forbid $\}$ for the government at Stage 1, is when $m<\mathbf{m}_{F}$ and

$$
(1-\lambda) \int_{\mu-w}^{0}((1-g)(r-\alpha-\beta-x)-g \theta x) f(r) d r+Z>(1-\lambda) \int_{\mu-w}^{0}(r-x) f(r) d r+Z
$$


which can be solved to

$$
x(1-\theta)>\frac{1}{2} m+\frac{(\alpha+\beta)(2-3 g)}{2 g}
$$

where we note that by $g<\frac{1}{2}$ we know that $(2-3 g)>0$. The above condition can be also written as

$$
m<3(\alpha+\beta)+2\left(x(1-\theta)-\frac{\alpha+\beta}{g}\right)
$$

and therefore the combination of this condition and $m<\mathbf{m}_{F}$ can be written as in (18).

Proof of Proposition 1. In (17), $\lambda$ only affects $\mathbf{m}_{F}$ as the second condition in (17) does not include $\lambda$. The expression for $\mathbf{m}_{F}$ from (33) can now be used to derive $\frac{\partial \mathbf{m}_{F}}{\partial \lambda}$ :

$$
\begin{aligned}
\frac{\partial \mathbf{m}_{F}}{\partial \lambda}= & -4 \alpha \beta g^{2}+(\alpha+\beta)^{2}\left(g(4+\lambda-g(3+4(1-g) \lambda))+(1-2 g)^{2} g \lambda-1\right) \\
& +(1-2 g \lambda) g(1-\theta) x(2(\alpha+\beta)(1-2 g)-g(1-\theta) x)
\end{aligned}
$$

which can be split into one term that is strictly positive (recalling that $g \in\left(0, \frac{1}{2}\right)$ ):

$$
(\alpha+\beta)^{2}\left(g(4+\lambda)+(1-2 g)^{2} g \lambda\right)+2(1-2 g \lambda) g(1-\theta) x(\alpha+\beta)(1-2 g)
$$

and another term that is strictly negative:

$$
-4 \alpha \beta g^{2}-(\alpha+\beta)^{2}\left(g^{2}(3+4(1-g) \lambda)+1\right)-(1-2 g \lambda) g^{2}(1-\theta)^{2} x^{2}
$$

Depending on parameter values, either (39) or (40) can dominate, meaning $\frac{\partial \mathbf{m}_{F}}{\partial \lambda}$ can take either sign. We can verify this using numerical examples (which satisfy the parameters conditions in (4)-(6)):

1. Setting $\alpha=0.01, \beta=0.1, g=0.4, \theta=0.5, x=0.1, m=0.03$, and evaluating $\frac{\partial \mathbf{m}_{F}}{\partial \lambda}$ at $\lambda=0.5$, gives $\frac{\partial \mathbf{m}_{F}}{\partial \lambda}=-0.005<0$.

2. Setting $\alpha=0.01, \beta=0.1, g=0.4, \theta=0.75, x=0.75, m=0.03$, and evaluating $\frac{\partial \mathbf{m}_{F}}{\partial \lambda}$ at $\lambda=0.5$, gives $\frac{\partial \mathbf{m}_{F}}{\partial \lambda}=0.047>0$.

Proof of Proposition 2. The government's expected payoff conditional on $r$ is identical to (27) over $r \in S$ and to (28) over $r \notin S$. Solving $r-x<(1-g)(r-\alpha-\beta)-x(1-g+g \theta)$ to $r$ gives the expression in (20).

Moreover, the government is a priori indifferent over policy options for $r \geq 0$, as gambles for resurrection only occur when $r<0$. It therefore optimally uses a mixed strategy over $r \geq$ 
0 to ensure that its policy profile for $r<0$ does not change priors about solvency. The optimal weights on $l=\{$ Allow $\}$ and $l=\{$ Forbid $\}$ in the mixed strategy can be any that satisfy $E[r \mid l=\{$ Allow $\}] \geq 0$ and $E[r \mid l=\{$ Forbid $\}] \geq 0$, which are always feasible to find given $E[r]>0$. This means that the public's initial prior of $r \geq 0$ does not change after observing either policy action.

Proof of Lemma 6. First note that in spite of the addition of the term $-\phi \eta(\rho-\bar{\rho})$, the bank continues to optimize over a convex function, because the convex form of (23) is not altered by a linear addition. Hence, the bank's optimization continues to boil down to a choose between $\rho=1$ and $\rho=0$.

Assume that the government sets $\bar{\rho}=0$ at Stage 1, as verified in the proof of Lemma 7 . Then the bank solves $\max _{\rho}\{E[\Pi]\}=$

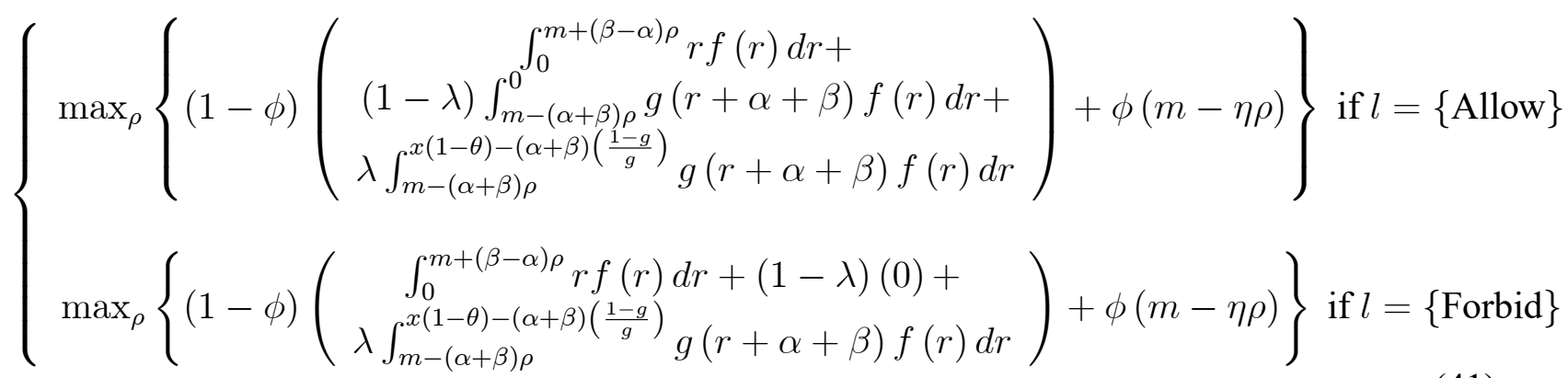

which means that from this point, the proof is identical to the proof of Lemma 4, except that, irrespective of whether $l=\{$ Allow $\}$ or $l=\{$ Forbid $\}$, the term $(m-\eta \rho)$ makes $\rho=1$ less attractive (i.e., the term is $m-\eta$ if $\rho=1$ and $m$ if $\rho=0$ ) than in the baseline model, which implies that $\widehat{\mathbf{m}}_{A}<\mathbf{m}_{A}$ and $\widehat{\mathbf{m}}_{F}<\mathbf{m}_{F} \cdot{ }^{22}$

Turning to the limit cases relative to $\phi$, we note that $\widehat{\mathbf{m}}_{A} \rightarrow \mathbf{m}_{A}$ and $\widehat{\mathbf{m}}_{F} \rightarrow \mathbf{m}_{F}$ for $\phi \rightarrow 0$ follow directly from the equivalence between (41) and (30) when $\phi \rightarrow 0$. Moreover, when $\phi \rightarrow 1$, we have that the bank optimizes only the term $(1-\eta \rho)$, which implies it always chooses $\rho=0$.

Proof of Lemma 7. When $\bar{\rho}$ is not binding, the government is ex-post indifferent about the chosen value of $\bar{\rho}$. Instead, when $\bar{\rho}$ is binding at Stage 3 then: with $\rho=0$, the government has a certain payoff of 0 , which is the highest attainable. Hence, with $\phi$ probability of preferring $\bar{\rho}=0$ and $(1-\phi)$ probability of indifference at Stage 3 , the government chooses $\bar{\rho}=0$ at Stage 1 .

For $l$, the steps of the proof are identical to those in the proof of Lemma 5. The payoff structure for the government (as seen from the stages of the game) in Section 5 is identical to that in Section 2.4, except for Stage 3 in Section 5. However, $l$ is optimally set as if the bank's arbitrage attempt is always successful and $\bar{\rho}$ is irrelevant, because when the bank's arbitrage fails and $\bar{\rho}=0$

\footnotetext{
${ }^{22}$ The term $\phi(m-\eta \rho)$ comes from the fact that when the bank cannot arbitrage the risk cap (with probability $\left.\phi\right)$, its risk profile is forced down to $\rho=0$ with certain payoff $m$, while it pays the portfolio adjustment $\operatorname{cost} \eta(\rho-\bar{\rho})$ where $\bar{\rho}=0$.
} 
binds $\rho$, then gambles can never occur ( $r>0$ is assured) and therefore $l$ is irrelevant (i.e., policy $l$ only applies when the bank's arbitrage succeeds).

Proof of Proposition 3. The continued validity of Proposition 1 follows directly from the equivalence between Lemmas 4 and 5, and, respectively, Lemmas 6 and 7, where the only differences are the replacements of $\mathbf{m}_{A}$ by $\widehat{\mathbf{m}}_{A}$ and $\mathbf{m}_{F}$ by $\widehat{\mathbf{m}}_{F}$.

The statement in the second sentence of Proposition 3 follows directly from (22) in comparison to (17): given $\widehat{\mathbf{m}}_{F}<\mathbf{m}_{F}$ from Lemma 6, the government chooses $l=\{$ Allow $\}$ for a smaller subset of possible values of $m>0$ in Lemma 7 than in Lemma 5. Equivalently, the government chooses $l=\{$ Forbid $\}$ for a larger subset of possible values of $m$ in Lemma 7 than in Lemma 5 . 